\title{
Problemática do Patrimônio Natural/Cultural no Brasil
}

\author{
Américo Pellegrini Filho *
}

turísticos. Madrid, $\mathrm{n}$.

RESUMO: Desde a década de 1930 existe, no Brasil, a preocupaçāo pela preservaçāo de recursos naturais e de bens culturais. Leis, campanhas de esclarecimento e outras providências caracterizam o empenho de estudiosos, ds vezes contra interesses econômicos de empresas e alienaçāo de largas faixas populacionais. Quando o tema alcança repercussäo internacional, espera-se um aceleramento da conscientização em torno da problemática e $o$ cumprimento de instrumentos legais.

UNITERMOS: Patrimônio: cultural, natural; memória nacional; recursos naturais; bens culturais.

ABSTRACT: Since the thirties, there have been in Brazil a constant apprehension regarding natural resources and cultural values. Laws, procedures and other forms of evoking consciousness of the problem have caracterize efforts even against private organizations purposes or large clusters of allienated population. When the issue come to affect international relations, it is expected an increase in awareness of the problem and its legal procedures.

KEY WORDS: Heritage natural, cultural; ecology; tradition; natural resources; cultural products.

\section{INTRODUÇÃO}

A preservação do patrimônio natural e cultural constitui um dos assuntos que vem despertando o maior interesse a nível mundial, principalmente a partir de 1980. Como conciliar conservação e progresso material? Esse tem sido muitas vezes um grande problema. $O$ ideal parece ser a preservação ativa, isto é, a conservação física dos bens patrimoniais, dando-se-lhes uma função conveniente, com soluçōes adequadas ao desejado progresso. Se de um lado os bens cul-

(*) Professor Doutor do Curso de Turismo da ECA/USP. ECA/USP - Cid. Univ. “Armando de Salles Oliveira” - Av. Prof. Lúcio M. Rodrigues, 443 - 05508 - São Paulo - SP - Brasil. 
turais - produtos da mão do homem .. recebem atenção que antigamente não tunham, por ourro lado os bens da natureza são alvo de cuidados especiais; a preocupação pela ecologia vem a ser, afinal, uma conseqüência dos danos ambientais causados por aspectos daquele progresso sem controles.

\section{PATrimônio CUltural}

\subsection{Mário de Andrade: Pioneiro}

No Brasil houve, na década de 1920 , algumas tentativas isoladas de projetos de lei visando a preservação do patrimônio cultural; enretanto, foi na década seguinte que se deu o grande passo nesse caminho. A Constituição Federal de 1934 estabelece, em seu art. 148, que compete ao Poder Público animar o desenvolvimento da cultura e proteger objetos de interesse histórico e artís ico. Para detalhar a formalização legal da determinação constitucional, o Ministério da Educação e Saúde de então convidou Mário de Andrade para redigir um anteprojeto. Colocando em ação sevi entusiasmo e sua competência, ele redigiu um texto bastante avançado ${ }^{1}$ pare a época, ainda mais se considerarmos que praticamente nada havia sido realizado nessa área, entre os brasileiros, a começar pela conceituação:

"Entende-se por Patrimônio Artstico Nacienal todas as obras de arte pura ou de arte aplicada, popular ou enuitita, nacional ou estrangeira. pertencentes aos poderes públicos, e a organismos sociais e a particulare.

Como se verifica, Mário de Andrade usa o significante "arte" para designar patrimônio cultural, e abrangendo oito categorias: "l-Arte arqueológica; 2 - Arte ameríndia; 3 -Arte popular; 4-Arte
histórica; 5 -Arte erudita nacional; 6 -Arte erudita estrangeira; 7 -Ar. tes aplicadas nacionais; 8 -Artes aplicadas estrangeiras".

\subsection{A Luta do Novo Orgâo}

Mas o Brasil estava sob a ditadura de Getúlio Vargas e despre parado para aplicar um texto legal com tais características; o anteprojeto sofreu mudanças lamentáveis, porém acabou por transformar-se no Decreto-Lei 25 , de 30 de novembro de 1937, que dá organızação ao SPHAN - Serviço do Paurimónio Histórico e Artísticc Nacıonal Idenominação que se fixaria nas décadas seguintes, va- riando entretanto a posiçăo hierárquica do órgão - Diretoria, Secretaria, Instituto etc., dai as siglas encontradas: DPHAN, IPHAN...).

Trata-se de um documento legal freqüentemente citado, porque organiza o SPHAN, que havia sido criado pela lei 378, de 13 de janeiro de $1937^{2}$. Nesse extenso decreto-lei, o que hoje em dia se denomina preferentemente "patrimônio cultural" é assim especificado:

\section{" $O$ conjunto dos bens móveis e imbveis existentes no País e cuja preser- vação seja de interesse público, quer por sua vinculaçäo a fatos memorá. veis da historia do Brasil, quer por seu excepcional valor arqueologico ou etnográfico, bibliográfico ou artístico"}

Para primeiro diretor do SPHAN foi nomeado o arquiteto Rodrigo Mello Franco de Andrade, também por indicação do escritor Mário de Andrade (o mesmo sobrenome não significa terem sido parentes; apenas coincidência). Pode-se imaginar as dificuldades que o arquiteto Rodrigo Mello Franco de Andrade teve de enfrentar para instalar e dar vid ao novo órgão, resumidas em: pouca verba e nenhum elemento humano especializado.

As atenções do SPHAN centralizaram-se no acervo arquitetôni$\operatorname{co}^{3}$ antigo brasieliro - remanescentes representativos do ciclo do açúcar na regiāo Nordeste do País; do ciclo do ouro em Minas Gerais e em pontos isolados; monumentos arquitetônicos em cidades litorâneas como Salvador, Rio de Janeiro, Recife, Olinda, Belém; e alguns outros casos, no extenso território. Sobressaem-se igrejas, na maior parte com decoração barroca; fortes levantados pelo colonizador português para proteger suas posses territoriais; sedes de fazenda; e alguns poucos conjuntos coloniais - na maior parte, testemunhos da elite dominante. Frente à ameaça de destruição sob que se achavam esses monumentos antigos - cerca de 200 anos de vida, para o Brasil, já é "antigo" - fazia-se necessária uma política de proteção com caráter de emergência, considerando a total falta de consciência do valor desses bens patrimoniais, na década de 1930. Mas o órgão federal destinado à preservação do patrimônio cultural brasileiro não dispunha de força política para impor suas decisōes, muito menos para criar essa consciência, nem a nível da população, nem mesmo a nível de autoridades (leia-se: governantes), de modo que muitos bens patrimoniais iam sendo destruídos, modificados ou vendidos quando se tratava de bens móveis.

Foi somente na década de 1970 que se realizaram reuniōes de especialistas e de autoridades, em Brasnia e em Salvador, nas quais se procuraram soluçōes para a valorização da preservação do património cultural e natural do país, dando-se a essa denominação um alargamento que, na prática, ela não vinha tendo (embora o antepro- 
jeto de Mário de Andrade tenha colocado ampla abrangência, com a devida indicação de bens móveìs além dos imóveis). Mas o Brasil atravessava outro período ditatorial, iniciado em 1964, e o regime tecnocrático-militar privilegiava um modelo econômico que não permitia nenhuma prioridade ao correto atendimento de necessidades da educação e da cultura; os governos militares massificaram a educação e até parece que desconfiavam da cultura como sendo um perigoso agente subversivo. Quaando, no final da década de 1970, se mostrou evidente o esgotamento do modelo econômico imposto, são criados alguns órgãos paralelos ao do Patrimônio Histórico e Artístico e, note-se, fora do âmbito do MEC: no Ministério da Indústria e Comércio e no do Planejamento. Isso se explica em função de iniciativas pessoais, como é o caso de Severo Gomes, então ministro da Indústria e Comércio. Anos depois, esses órgãos foram fundidos com a lei 6.757/79, que cria a Fundação Nacional Pró-Memória; decide-se que à SPHAN caberiam funções normativas e à Pró-Memória funçōes operacionais. Essas mudanças (para melhor) devem-se principalmente à capacidade e ao entusiasmo do designer Aloísio Magalhães, que se sobrepôs a circunstâncias políticas. ${ }^{4}$

\subsection{Novas Providências}

Nos anos oitenta, é de se notar uma grande evolução na conscientização da importância de se preservar o patrimônio cultural, tomada essa expressão de modo abrangente - não apenas artefatos representaivos da elite, mas também de grupos minoritários (indígenas, negros, ciganos e outros) e de estratos populacionais não privilegiados (esrravos, operários, imigrantes na passagem do século XIX para o XX, e outros), além de manifestaçōes espirituais implicando documentação (com equipamento de filmagem, fotografia, gravação, etc). Enfín, era o que Mário de Andrade havia sugerido em 1937. O reconhecimento, pela UNESCO, de conjuntos excepcionais como "Bens da Humanidade" - Ouro Preto (MG), São Miguel das Missōes (RS), Pelourinho (BA) e outros - veio reforçar essa conscientização, contra a ganância da especulação imobiliária por um lado e a ignorância por outro. Na Constituição Federal de 1988, o parrim6́nio cultural é especificado em alíneas dos artigos 23, 24, 215 e 216 (estes dois formando o capítulo "da cultura"); e os traços culturais dos indígenas sảo respeitados, conforme declarado no art. 231. 58

Leis existem; o problema está em fazê-las cumprir.

\section{PATRIMÔNIO NATURAL}

Os cuidados para com a preservação do patrim6nio natural se difundiram bem mais recentemente. $E$ a dificuldade $\varepsilon$ a mesma: fazer cumprir as leis. Por exemplo: a Constituição reserva todo um capítulo ao "meio ambiente", com o art. 225 (incluindo seis parágrafos e sete alíneas). Nesses dispositivos, fica declarado que compete ao Poder Público preservar "os processos ecológicos essenciais e prover o manejo ecológico das espécies e ecossistemas", proteger a fauna e a flora etc. além de eleger como patrimônio nacional nada menos que "a Floresta Amazónica, a Mata Atlântica, a Serra do Mar, o Pantanal Mato-Grossense e a Zona Costeira". Mas surge uma dificuldade: como obter recursos (materiais e elemento humano) para fiscalizar e proteger adequadamente áreas de valor excepcional espalhadas em mais de 8.500 .000 quilômetros quadrados?

Com a moderna tecnologia, entretanto, pode-se obter algum controle. É o caso da documentação fotográfica colhida por satélites como o Landsat e o Noaa-9, para se descobrirem queimadas em florestas. O controle em terra, porém, continua dificultoso. Órgãos federais incumbidos da tarefa chegaram a ser inteiramente desacreditados (o Instituto Brasileiro de Desenvolvimento Florestal - IBDF serviu para se brincar com o D da Sigla: "Destruição"); até que o governo criou o Instituto Brasileiro de Meio Ambiente e Recursos Naturais Renováveis - IBAMA, englobando o IBDF, a Sudepe, a Sudhevea e a SEMA. Além disso, medidas e discursos de impacto têm sido efetuados, inclusive o programa "Nossa Natureza"; mas como evitar, e com quais recursos efetivos, que vinte milhōes de hectares sejam queimados (dados de 1987 segundo o satélite Noaa-9 e o Instituto Nacional de Pesquisas Espaciais), que espécies como a arara azul, o muriqui, a ariranha, o mico-leão-dourado, o jacare sejam dizimadas $?^{5}$ Estima-se que há espécies vegetais ainda não classificadas, e que ardem nas fogueiras provocadas pela especulação de multinacionais (e de nacionais tambÉm), em favor de seus esquemas de agropecuária empresarial destinada à exportação6. Na celeuma sobre a problemática ecologia $x$ dívida externa, o Brasil parece amadurecer um projeto que envolve programas de preservação, transferéncia de tecnologia, talvez cooperação financeira sem penda de soberania nacional. Entretanto, o assunto explode também a nivel regional e até local, com despejos de vinhoto, mercúrio, agrotóxicos, o perigo do uso de CFC (clorofluorcarbono) e outros fatores poluentes. 


\subsection{A Prática, na Defesa da Ecologia}

Dezenas de entidades particulares têm atuado ${ }^{7}$ nesse relativamente acelerado processo de conscientização da necessidade de protegermos nossa "casa" (oikos em grego, daí ecologia). Até em pequenas cidades atuam associaçōes de entusiastas, ecologistas ou não. Nesse caminho, criam-se parques e reservas estaduais e municipais, tenta-se o eco-turismo ou turismo ecológico, jornais e revistas dedicam consideráveis espaços ao meio ambiente, defende-se a agricultura ecológica, ${ }^{8}$ fazem-se campanhas pela ecologia, e a preservação ambiental no Brasil é motivo para promoçōes no exterior ${ }^{9}$. Embora tais iniciativas sejam importantes, sempre resta, porém, o perigo de se repetirem erros como os da hidrelérica de Balbina ${ }^{i 0}$, os de incentivos à instalação de vastas fazendas de pasto, os da abertura de estradas contrariando sondiçōes ambientais... quer dizer: grandes obras levando ao desequilíbrio de ecossistemas.

\subsection{Considerações Finais}

A respeito do avanço com que a Constituição considera a problemática do patrimônio natural e cultural, os brasileiros têm muito que aprender nessa área. Quando se observa o trato que outras naçōes dão ao seu acervo natural e cultural, pode-se compreender que existe um longo caminho a ser percorrido e que passa, de início, pela conscientização. Nesse sentido, a atuação de órgãos de comunicação social e de professores em todos os níveis é importantíssima. Para que os dispositivos legais não permaneçam no papel, é preciso que desde o trabalhador braçal até o grande empresário, incluindo-se o importante público infanto-juvenil, todos compreendam o benefício social possível de se obter com a preservação ativa da natureza e de bens culturais. Se alguns lugares e artefatos, ou manifestações espirituais de valor excepcional, exigem proteção mais ampla e até proteção total, muitos outros permitem seu uso racional, em atividades de lazer, de turismo, de agro-indústria, de esportes etc.; naturalmente, mediante planejamento norteado por uma visão moderna do tema.

Assim, não se estará repetindo erros já cometidos por países desenvolvidos, que hoje reclamam do Brasil medidas protecionistas que eles não tomaram.

\section{NOTAS}

1 Carlos Lemos acentua a clarividência de Mário no anteprojeto, pois aplicou "uma sistemática somente hoje em nossos dias divulgada pelas entidades e recomendaçōes internacionais, que tratam modernamente do assunto"; LEMOS, C. O que é pa trơmónio histórico, São Paulo; Brasiliense, 1981, p. 41.

2. No cap. III, secçåo III, art. 46 da Lei 378/37, o SPHAN recebe a "finalidade de promover, em todo o país e de modo permanente, o tombamento, a conservação, o enriquecimento e o conhecimento do património histórico e artístico". A Lei 378 foi publicada no Díário Oficial em 15 de janeiro de 1937; seu complemento, o Decreto Lei 25 , foi publicado no mesmo órgâo federal em 6 de dezembro e 11 de dezembro de 1937.

3. Acentue-se que, na época, a expressão "património histórico e artístico" parecia sinónima de "património arquitetónico".

4. Aló́sio Sérgio de Magalhāes faleceu em 1982, quando representava o Brasil em reuniāo de especialistas, na Itália. O estatuto da Pro-Memória foi aprovado pelo Decr. 84.398/80. Com as Medidas Provisórias do "Plano Collor", em março de 1990 novas modificaçōes foram efetuadas na área federal da Cultura, incluindo-se a área de preservaçāo da memória nacional.

5. Uma lista do IBDF, datada de 1973, indica que havia mais de 90 espécies de animais em extinçāo, no Brasil

6. Ver LUTZENBERGER, José. Ecologia. Porto Alegre: LAPM, 1985. Com freqüência, a imprensa, o rádio e a televisão têm tratado do assunto.

7 Destaque para a SOPREN - Sociedade de Preservação de Recursos Naturais e Culturais da Amazónia (Belém) e a Fundaçāo SOS Mata Atlântica (São Paulo); há entidadesirmãs em vários países, recebendo verbas e orientaçāo do exterior, como a FUNATURA - Fundaçāo Pró Natureza (Brasília).

8. Ver LUTZENBERGER, José. Ecologia. Porto Alegre: L\&PM, 1985.

9. As "andanças" do cantor inglês Sting junto com o cacique txucarramãe Raoni, iniciadas em abril de 1989, constituem um exemplo que associa as pressōes de autoridades européias com a repercussāo popular

10. A represa de Balbina, cerca de 145 quilómetros ao norte de Manaus e formada por águas do rio Uatumā, constitui um dos maiores erros de planejamento para aproveitar mecursos da natureza com o agravante de que havia precedentes no exteriore lar recuros da nus Pais Inadis prejuizos ecologicos, sociais e economicos. quebra do equillbrio do ecossistema danos a caboclos e a indigenas (desrespeitando areas legalmente reservadas ao waimir e aos atroári), custos enormes que não justificam a baixa produtividade de energia elétrica. O fechamento da barragem se deu em 1987, e suas consequêencias levaram a própria Eletronorte a admitir o erro de sua construção.

$\mathrm{Na}$ imprensa podem-se encontrar muitas matérias interessantes, tais como: PEREI RA, Jose Matias. O impacto das hidrelétricas na ecologia da Amazónia. Folha de $S$ Paulo, 4/11/1987; BALBINA - um escândalo ecológico. Jomal do Campus, 25/11/1987: BALBINA era desnecesćria, afima biólogo. $O$ Estado de $S$. Paulo. 20/01/1989

Declaraçōes de elementos do governo federal empossado em 1990 retomam a in tenção de se construírem outras hidrelétricas na Amazônia, contrariando opinióes de técnicos. 